\title{
TRACKING ANXIETY DISORDERS IN ANKYLOSING SPONDYLITIS WITH THE GAD-7 QUESTIONNAIRE
}

Guilherme Lopes Pereira (Universidade de Fortaleza, Fortaleza, CE, Brasil), Adah Sophia Rodrigues Vieira (Universidade de Fortaleza, Fortaleza, CE, Brasil), João Guilherme Farias de Sá Gomes (Universidade de Fortaleza, Fortaleza, CE, Brasil), Lísia Laiane Abreu Gomes Loiola (Universidade de Fortaleza, Fortaleza, CE, Brasil), Joerun de Carvalho Oliveira (Hospital Geral de Fortaleza, Fortaleza, CE, Brasil), Jokasta Nunes Lobo (Hospital Geral de Fortaleza, Fortaleza, CE, Brasil), Rejane Maria Rodrigues de Abreu Vieira (Hospital Geral de Fortaleza e Universidade de Fortaleza e Universidade Estadual do Ceará, Fortaleza, $\mathrm{CE}$, Brasil)

\section{BACKGROUND}

Anxiety disorders are prevalent and can be disabling when not diagnosed. In chronic diseases, this symptom is often underestimate. Ankylosing spondylitis (AS) is a chronic disease that affects young adults, with implications for both the physical and mental health of those affected. A prolonged coexistence with pain and deformity that the illness causes often implies alterations and emotional disorders in these patients.

\section{MATERIALS AND METHODS}

Quantitative cross-sectional study based on the data collected through an application of the Generalized Anxiety Disorders (GAD-7) questionnaire. It's an instrument used to assess these anxiety disorders, validated in Brazil in 2006. It presents seven items with scores from 0 to 3 in each one, and the total score ranging from 0 to 21 . Values higher than or equal to ten are correlated with a generalized anxiety disorder. The Ethical Committee approved the study of research, and the participants filled the free and clarified consent term.

\section{RESULTS}

The study involved a total of 104 patients with Ankylosing spondylitis, and $74 \%$ were male, with an age range below 45 years seen in $60 \%$ of the sample. The level of schooling above seven years presented in almost $70 \%$ and disease time above six years in this same proportion. Smoking and alcohol consumption observed in $10 \%$ and $21 \%$, respectively. Forty-three percent of the sample was professionally active, almost $30 \%$ were unemployed, and $27 \%$ were retired. A score greater than or equal to 10 in the total sum of GAD-7 was found in $38 \%$ of the patients, thus, filling criteria for generalized anxiety disorder. Twothirds of the patients diagnosed with an anxiety disorder had schooling above seven years of study. The average GAD-7 score of the positive cases was 12 .

\section{CONCLUSION}

An anxiety disorder diagnosed in more than one-third of patients with AS. The level of education showed a positive correlation with this diagnosis. The use of an appropriate instrument, such as GAD-7, to assess anxiety may be a device for the determination of this comorbidity, which is very frequent and compromises the well being of those who live with it. 